\title{
Research on the Online Cleaning of Heat Exchanger in Crude Oil Processing System
}

\author{
Su Yan, Zhengyu Cao, Meirong Lian, Yingfan Liu, Jinhui Zhu ${ }^{\mathrm{a}}$ \\ CNOOC Energy Conservation \& Environmental Protection Service Co., Ltd., Tianjin 300452,

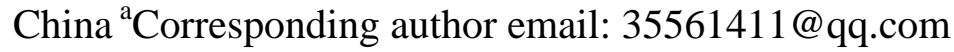

Keywords: Online cleaning; Crude oil; Heat exchanger; Cleaning ball; Collecting time

\begin{abstract}
Fouling in heat exchangers for crude oil not only increases the heat resistance affecting the heat transfer efficiency, but also enhance the flow resistance increasing the energy consumption and even leading to safety problems. This paper performs a special kind of cleaning ball made of stainless steel fiber and boron-silicon rubber which is compatible to crude oil, to clean the tube side of a shell and tube heat exchanger. The online cleaning experimental results show that the collecting time of cleaning ball in the automatic tube cleaning system for oil (ATCSO) increase as the number of cleaning balls increases. The online cleaning effects are satisfying by using the cleaning balls since the crude oil temperature at the outlet of the heat exchanger increases quickly after a short time cleaning, which means that the heat transfer is improved effectively.
\end{abstract}

\section{Introduction}

An oil refinery or petroleum refinery is an industrial process plant where crude oil is processed and refined into more useful products such as petroleum naphtha, gasoline, diesel fuel, asphalt base, heating oil, kerosene, and liquefied petroleum gas [1]. Fouling is generally defined as the deposition and accumulation of unwanted materials such as scale, algae, suspended solids and insoluble salts on the internal or external surfaces of processing equipment including boilers and heat exchangers. Fouling in heat exchangers is one of the major problems in chemical process industries, especially in refineries and considered as the main source for energy loss, reaching up to $2 \%$ of the refinery's total energy consumption. In the recent years, due to the challenging refinery margins, there is a profound interest in minimizing the energy consumptions in all oil refinery applications. As fouling formation occurs, the heat transfer capacity of the exchangers decrease; thus higher heat load is required in the furnace which leads more fuel gas/ fuel oil consumption in the furnace. Also, the amount of greenhouse gas emissions increase [2]. Fouling in the crude oil preheat trains is considered as around 20\% of all heat exchanger fouling [3]. Various methods have been adopted to study the complex problem of fouling in crude oil heat exchangers [4]. Research using actual plant data is slow, subject to a variety of logistical and operational requirements which do not lend themselves well to fundamental scientific studies [5], and can present difficulties in the interpretation of the thermal data [6]. A number of laboratory methods have been developed to study liquid phase fouling [7-8] including for crude oils use of the stirred batch cell [9], or use of a recycle flow loop with either a tubular cross section [10] or an annular cross section [11-12]. Chao Shen et al. [13] investigated the effects of velocity and installation location of a shell-and-tube heat 
exchanger on particle fouling deposited within the heat exchanger, which is also helpful to crude oil system.

The aim of this paper is to build an experimental system to research the online cleaning of heat exchanger in crude oil processing system.

\section{Crude Oil Properties and Ultimate Analysis}

In order to obtain the real data which can be performed in the current crude oil processing plants, the crude oil used in this experiment is from a crude oil and gas treatment plant of China National Offshore Oil Corporation (CNOOC). The properties and ultimate analysis are shown in Table 1.

Table 1 Crude oil properties and ultimate analysis

\begin{tabular}{|c|c|c|c|c|c|c|}
\hline $\begin{array}{c}\text { Density } \\
\left(\mathrm{kg} / \mathrm{m}^{3}\right) \\
\text { at } 50^{\circ} \mathrm{C}\end{array}$ & $\begin{array}{c}\text { Viscosity } \\
(\mathrm{mPa} \bullet \mathrm{s}) \\
\text { at } 50^{\circ} \mathrm{C}\end{array}$ & $\mathrm{N}(\%)$ & $\mathrm{C} \mathrm{( \% )}$ & $\mathrm{H}(\%)$ & $\mathrm{S}(\%)$ & $\mathrm{O}(\%)$ \\
\hline 952.6 & 1171 & 0.636 & 84.101 & 10.977 & 0.116 & 0.448 \\
\hline
\end{tabular}

The density and viscosity of the crude oil at $50^{\circ} \mathrm{C}$ are $952.6 \mathrm{~kg} / \mathrm{m}^{3}$ and $1171 \mathrm{mPa} \bullet$ s, respectively. These properties are very important to fouling and cleaning during the process. The cleaning ball is made of stainless steel fiber and boron-silicon rubber. This cleaning ball is tested in this crude oil and it is very compatible with the oil.

\section{Experimental System}

Figure 1 shows the experimental system of online cleaning technology for crude oil processing system. In this test system, there are crude oil tank and heat transfer oil tank. The former has a cooler using water cooling system and the latter has an electrical heater to keep the heat transfer oil at higher temperature. Therefore, after the crude oil and heat transfer oil pass through the heat exchanger, the crude oil is heated and the heat transfer oil is cooled. Automatic Tube Cleaning System for Oil (ATCSO) is installed for online cleaning. Figure 2 shows the on-site situations. 


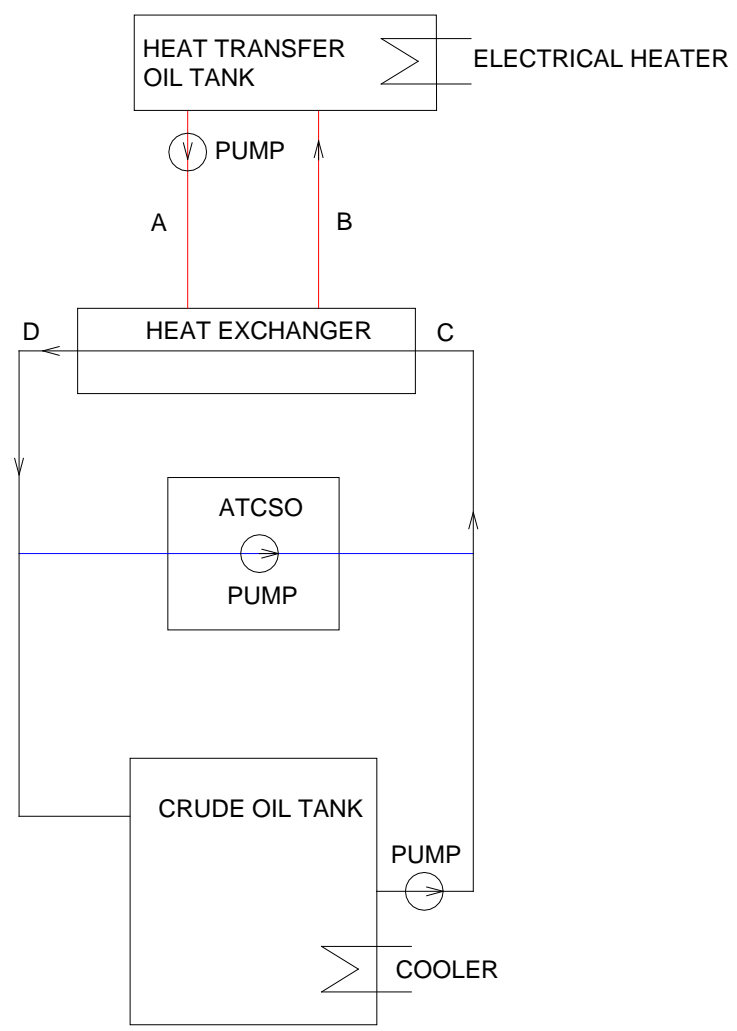

Figure 1. Schematic diagram of online cleaning system

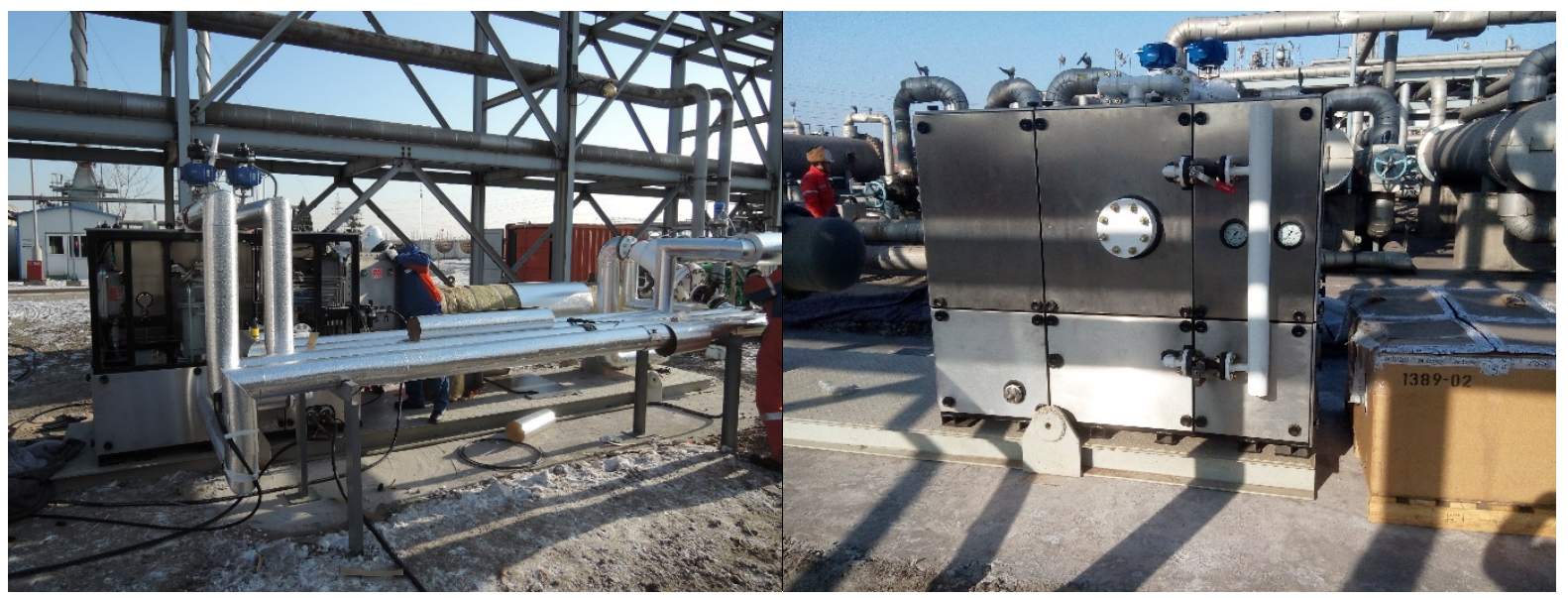

Figure 2. On-site pictures of online cleaning system

\section{Results and Discussions}

\subsection{Collecting Time and Number of Cleaning Balls}

The collecting time is the time period between the balls coming out from the outlet of ATCSO and the all balls arriving at the inlet of ATCSO startup. The collecting time was tested as the number of cleaning balls changed from 5 to 60 . For example, it will take 165 s to collect the all 5 
cleaning balls. With the increase of cleaning balls, the collecting time increases quickly and then gradually. The collecting time is 205 s as 60 cleaning balls are put into the ATCSO.

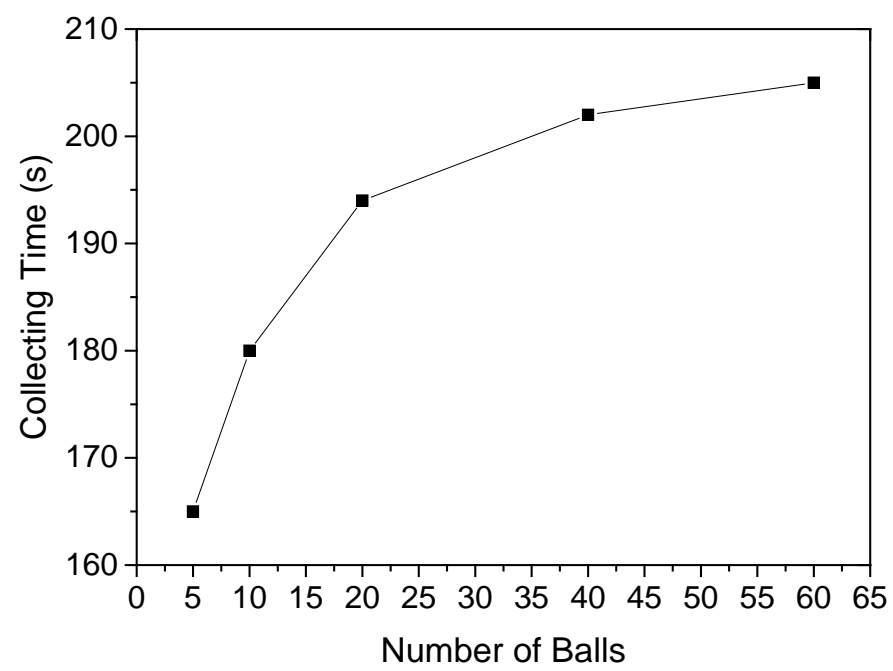

Figure 3. Collecting time changing with the number of balls.

\subsection{Crude Oil Temperature Changing with Time}

The temperature of heat transfer oil at the position A shown in Figure 1 is constant $\left(300^{\circ} \mathrm{C}\right)$ which is controlled by the electrical heater. The inlet temperature of crude oil at the heat exchanger is also constant $\left(220^{\circ} \mathrm{C}\right)$. The flowrates of both heat transfer oil and crude oil maintain unchanged. The crude oil temperature at the outlet of heat exchanger is shown in Figure 4 as the time goes. At the beginning, the crude oil temperature at the outlet (position D shown in Figure 1) reaches $290^{\circ} \mathrm{C}$. However, two hours later, it reduces to $287.5^{\circ} \mathrm{C}$. At this time, ATCSO with 60 cleaning balls starts up working for 6 minutes for cleaning. The crude oil temperature at the outlet increases to $289.9^{\circ} \mathrm{C}$ at 2.1 hours. which is very close to the temperature at the beginning of running. This means that the cleaning balls work very well to clean the tube side of the heat exchanger. As the time goes, the temperature decreases again, and with the startup of ATCSO for 6 minutes cleaning it goes up again and then down again. After the cleaning to the heat exchanger, the outlet temperature increases, which shows the heat transfer is enhanced. This is very helpful to improve the heat transfer efficiency. 


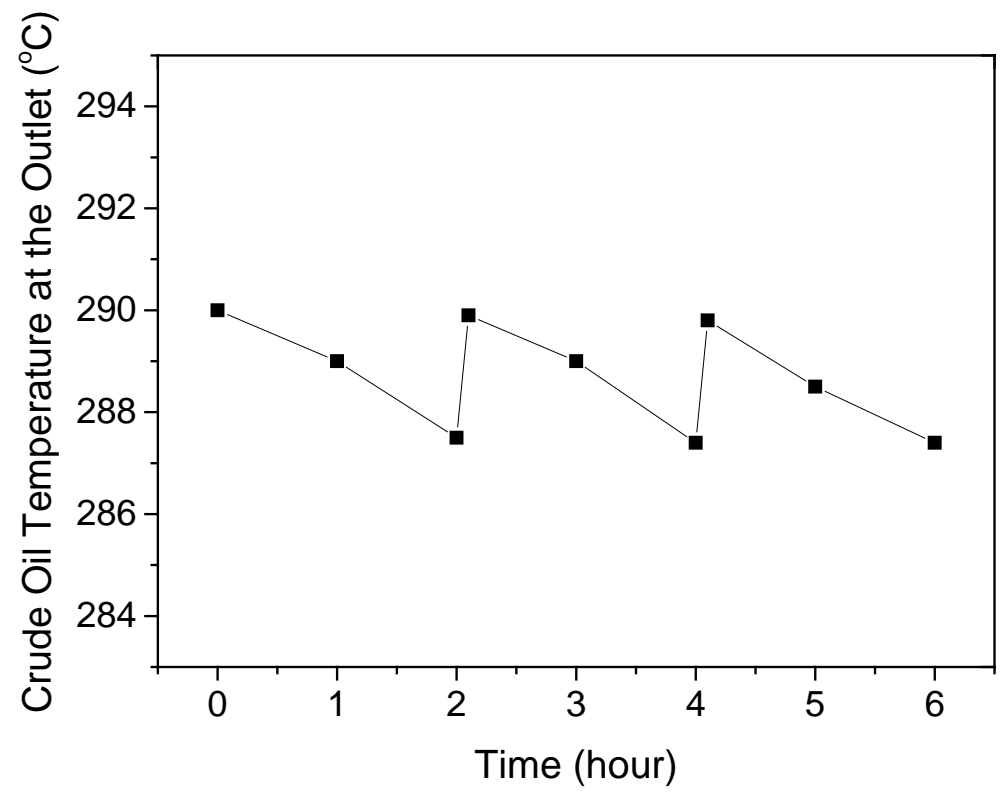

Figure 4. Crude oil temperature at the outlet (position D) changing with time

\section{Conclusion}

In this work, the experimental system was built to research the cleaning effect of the automatic tube cleaning system for oil by using the cleaning ball made of stainless steel fiber and boron-silicon rubber. The collecting time increases as the increase of cleaning balls. The change of the crude oil at the out of the heat exchanger shows that the cleaning ball can remove the fouling very well and enhance the heat transfer of the shell and tube heat exchanger for crude oil.

\section{Acknowledgements}

This work was financially supported by the International S\&T Cooperation Program of China (No. 2013DFG42440).

\section{References}

[1] https://en.wikipedia.org/wiki/Oil_refinery.

[2] H. Erdener Akınç, M. Becer, M. Bakır, Y. Özçelik, F. Balkan. Fouling monitoring in crude oil preheat trains. Proceedings of International Conference on Heat Exchanger Fouling and Cleaning, June 09 - 14, 2013, Budapest, Hungary, 18-21.

[3] J Aminian, S Shahhosseini. Evaluation of ANN modeling for prediction of crude oil fouling behavior. Applied thermal engineering. 2008, 28 (7), 668-674.

[4] Andrew Young, Silvia Venditti, Cesur Berrueco, Mengyan Yang, Andrew Waters, Haddy Davies, Simon Hill, Marcos Millan, Barry Crittenden. Characterisation of crude oils and their fouling deposits using a batch stirred cell system. Proceedings of International Conference on Heat Exchanger Fouling and Cleaning VIII. June 14-19, 2009, Schladming, Austria, 17-26.

[5] B. D. Crittenden, S. T. Kolaczkowski, I. L. Downey. Fouling of crude oil preheat exchangers, Trans IChemE Part A, 1992, 70, 547-557. 
[6] T. Takemoto, B. D Crittenden., S. T. Kolaczkowski. Interpretation of fouling data in industrial shell and tube heat exchangers, Trans IChemE Part A, 1999, 77, 769-778.

[7] N. Epstein. Fouling in heat exchangers, in Fouling of Heat Transfer Equipment, eds. E. F. C. Somerscales and J. G. Knudsen, Hemisphere, Washington, 1981, 701-732.

[8] Chenoweth J. M. Liquid fouling monitoring equipment, in Fouling Science and Technology, eds. L. F. Melo, T. R. Bott and C. A., Kluwer Academic Publishers, Dordrecht, 1988, 49-65.

[9] P. Eaton, R. Lux. Laboratory fouling test for hydrocarbon feed-stocks, ASME-HTD, 1984, 35, 33-42.

[10] B. D. Crittenden, S. T. Kolaczkowski, D. Z. Phillips. Crude oil fouling in a pilot-scale parallel tube apparatus, Heat Transfer Engineering, 2009, 30, 777-785.

[11] D. I. Wilson, A. P. Watkinson. Model experiments of autoxidation reaction fouling, Trans IChemE Part A, 1995, 73, 59-68.

[12] C. A. Bennett, R. S. Kistler, K. Nangia, W. Al-Ghawas, N. Al-Hajji, A. Al-Jemaz. Observation of an isokinetic temperature and compensation effect for high temperature crude oil fouling, Heat Transfer Engineering, 2009, 30, 794-804.

[13] Chao Shen, Chris Cirone, Liangcheng Yang, Yiqiang Jiang, Xinlei Wang. Characteristics of fouling development in shell-and-tube heat exchanger: Effects of velocity and installation location. International Journal of Heat and Mass Transfer, 2014, 77, 439-448. 